\title{
LAS EPIDEMIAS DEL MÉXICO PREHISPÁNICO: UN BREVE RECORRIDO HISTÓRICO
}

\section{The Epidemics of Prehispanic Mexico: A Brief Historic Overview}

\author{
Itza Nahomy GUTIÉRREZ FONSECA \\ Escuela de Enfermería. Cruz Roja Mexicana (México). \\ Correo electrónico: itza.nahomy@gmail.com
}

Fecha de recepción: 25 de julio de 2020

Fecha de aceptación: 11 de agosto de 2020

Fecha de publicación: 29 de enero de 2021

\begin{abstract}
Resumen
La Historia nos provee de algunos elementos para conocer las epidemias que los pueblos mesoamericanos enfrentaron inclusive antes de la llegada de los conquistadores. El arribo de las tropas de Hernán Cortés y las batallas antes los mexicas no solo hicieron el encuentro de dos cuerpos militares, sino de ejércitos invisibles, pero aún más potentes, que se manifestaron como enfermedades con consecuencias desastrosas para las poblaciones indígenas. Los cronistas de aquella época narraron los sucesos y efectos de estas olas epidémicas. A través de la revisión de Códices como el Florentino, Telleriano-Remensis y De la Cruz-Badiano, así como del testimonio de uno de los actores de esos primeros tiempos de la conquista, Bernardino de Sahagún, podemos hacer un recuento de las principales pandemias sufridas por las poblaciones prehispánicas en un periodo que abarca de 1446 a 1576.
\end{abstract}

Palabras clave: epidemias; historia; conquista.

\section{Abstract}

History provides us some elements to know about the epidemics that Mesoamerican people faced even before the coming of conquerors. The arrival of Hernán Corté's troops and the battles against the Mexica, not only made the encounter of two military units but also of another one, an invisible, and more powerful army that manifested itself in diseases with unfortunate consequences 


\section{LAS EPIDEMIAS DEL MÉXICO PREHISPÁNICO: UN BREVE RECORRIDO HISTÓRICO ITZA NAHOMY GUTIÉRREZ FONSECA}

for indigenous populations. The chroniclers of the time narrate the events and effects of these epidemic waves. Through the review of Codex such as Florentino, Telleriano-Remensis and De la Cruz-Badiano, as well, the testimony of one of the principal actors of those early time of Conquest, Bernardino de Sahagún, we can make an account of the main pandemics suffered by pre-Hispanic populations from 1446 to 1576.

Keywords: epidemics; history; conquest.

\section{BREVE RECORRIDO HISTÓRICO DE LAS EPIDEMIAS PREHISPÁNICAS}

En el 2019 se cumplieron 500 años del encuentro entre Moctezuma y Hernán Cortés, la confluencia de dos mundos, el indígena y el español, situación que dio paso a la conquista y creación de la Nueva España. No fue sino hasta agosto de 1521 cuando con la caída de Tenochtitlan, se concluye este proceso para iniciar otro de colonización y evangelización que duraría casi tres siglos en el territorio que actualmente es México.

El 2020 coincide, fatídicamente también, con los 500 años de una de las pestes más agresivas sufridas en el México antiguo. Los cronistas de aquella época ${ }^{1,2,3}$ y algunos historiadores contemporáneos ${ }^{4,5,6}$ mencionan la relevancia que tuvieron las epidemias para el avance de los conquistadores en territorios mesoamericanos.

Tradicionalmente se considera que, al arribo de los españoles a tierras americanas, las enfermedades con altos índices de mortalidad aparecieron súbitamente entre los nativos. Efectivamente, surgieron nuevos virus a los cuales la población indígena no era inmune. Sin embargo, Malvido y Carral $^{4,6}$ sostienen que los indígenas ya habían enfrentado otros brotes epidémicos con características diferentes, pero también con efectos negativos, aunque no de la magnitud ocurrida para las siguientes décadas con la presencia de los hispanos.

El hecho de asignarles un nombre y un tratamiento posible, dice Carral $^{6}$, es un indicativo de que se comprendían sus posibles causas y efectos.
Entre las pestes conocidas previas a la conquista, se sabe que como efecto del agua contaminada hubo un alto índice de padecimientos gastrointestinales en 1446 y 1448, y se presume que fue el cólera el que diezmó a una parte de la población.

Seguidamente, en el período de 1450 a 1454, las sequías prolongadas ocasionaron hambrunas en las zonas circundantes de Tenochtitlan y Texcoco siendo proclives a contraer un alto número de infecciones y en otros casos, muertes, debido a un sistema inmunitario deprimido.

Por otro lado, el descenso inusitado de la temperatura en el Valle de Anáhuac en 1450 cobró una tasa importante de víctimas de edad avanzada debido a "catarros pestilenciales", se especula que fue un tipo de influenza epidémico. Aunque para 1455 la temporada de lluvias fue estable, las epidemias siguieron cobrando muertes ${ }^{5}$, incluso un año después de un provechoso periodo de cosechas.

$\mathrm{Si}$ bien entre las poblaciones mesoamericanas existía un alto grado de conocimientos médicos y tratamientos para aliviar las enfermedades, la cosmología mágico-religiosa nunca fue descartada y por ello, el tránsito del cometa Halley en el año de 1456 por la Tierra fue considerado como un mal augurio:

"Esta señal tuvieron de mal agüero; porque estos indios (también como nosotros los castellanos) conocen de ellas significar hambres, pestilencias y guerras como en esta ocasión se verificó"7.

Mandujano et al. ${ }^{5}$ hacen referencia a las migraciones originadas a partir de esta señal. Los aztecas, por ejemplo, donde a consecuencia de epidemias como posibles difterias, tifo 


\section{LAS EPIDEMIAS DEL MÉXICO PREHISPÁNICO: UN BREVE RECORRIDO HISTÓRICO ITZA NAHOMY GUTIÉRREZ FONSECA}

exantemático o alteraciones de las vías respiratorias, hicieron que los habitantes de Chalco, Xochtlan, Tequantépec y Amaxtlan fueran asolados por ellas. Esta ola mortífera no fue privativa para la población de estas regiones, incluso la caída de ciudades importantes como Tula o Mayapán -esta última zona maya-, fueron devastadas por las mismas razones. No es extraño entonces que este cúmulo de afecciones encarnara entre los indígenas un símbolo de destrucción.

El cronista Sahagún ${ }^{2}$ relató las diez señales consideradas como los pronósticos de mala suerte. El primero de ellos dice:

Diez años antes que viniesen los españoles a esta tierra pareció en el cielo una cosa maravillosa y espantosa, y es, que pareció una llama de fuego muy grande... esto duró por espacio de un año cada noche: comenzaba en las doce casas, y cuando aparecía a la media noche toda la gente gritaba y se espantaba: todos sospechaban que era señal de algún gran mal.

El conjunto de signos dio a la población prehispánica una idea de que todas estas enfermedades, inundaciones y sequías no eran sino resultado de su mal comportamiento con sus dioses, por ello, se esmeraban en ofrendar el mayor número de sacrificios y regalos para evitar las calamidades.

Incluso, previa a la toma de Tenochtitlan, Sahagún ${ }^{2}$ escribió:

Antes que los españoles que estaban en Tlaxcala viniesen a conquistar México, dio una grande pestilencia de viruelas a todos los indios... esta pestilencia mató gentes sin número, muchas murieron porque no había quien pudiese hacer comida; los que escaparon de esta pestilencia quedaron con las caras ahoyadas, y algunos los ojos quebrados.

\section{LOS ENCUENTROS FATÍDICOS}

A partir de la llegada de los españoles a tierras mexicanas, se da cuenta de los primeros brotes epidémicos ${ }^{8}$ :

Llegó en 1520 en uno de los navíos que trajeron las fuerzas de Pánfilo de Narváez; venía enfermo de viruela, y cuando salió a tierra, fuelas pegando a los indios de pueblos en pueblo y cundió de tal suerte esta pestilencia, que no dejó rincón sano en la Nueva España.

En su Relación de la venida de los españoles y principio de la ley evangélica, Fernando de Alva |xtlilxóchit $\left.\right|^{9}$, historiador novohispano y descendiente directo de la casa de Texcoco, refirió el fallecimiento de Cuitláhuac, hermano y sucesor de Moctezuma, a causa de la pestilencia: "El rey Cuitlahuatzin no gobernó más que cuarenta días, porque luego murió de unas viruelas que trajo un negro".

La viruela fue conocida entre los indígenas como hueyzáhuatl, cuyo significado es gran sarna o gran lepra. El pronto deceso de uno de los principales de la sociedad mexica nos indica de la violencia con que las epidemias atacaron a la población en tan corto tiempo, aún antes de la caída de la gran ciudad de Tenochtitlan reduciendo significativamente la cifra de habitantes, Carral estima en 8 millones las muertes solo para ese año de 1520. De acuerdo con Sahagún, la propagación de esta peste fue desde el 30 de septiembre al 19 de octubre de ese año, a punto de finalizar la fiesta de Paquetzaliztli.

Vale la pena ampliar un poco sobre la continua mención de los cronistas del origen de la transmisión de la viruela por parte de un negro.

La esclavitud fue reconocida en las Antillas a partir de $1501^{5}$ por medio de un decreto que validaba la transportación de personas negras nacidas en cautiverio en áreas cristianas hacia

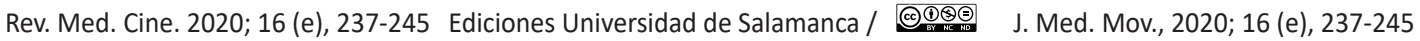
[ 239 ] 


\section{LAS EPIDEMIAS DEL MÉXICO PREHISPÁNICO: UN BREVE RECORRIDO HISTÓRICO ITZA NAHOMY GUTIÉRREZ FONSECA}

La Española, territorios que actualmente ocupan República Dominicana y Haití.

Quizá estos nacimientos no fueron abundantes para aquella época, sin embargo, es muy probable que hubiese un tráfico de esclavos desde África para llevarlos a las nuevas tierras, el cual no estuvo exento de enfermedades durante la travesía. La mortandad de esclavos se calcula en proporciones mayores al $30 \%$ en los siglos que van del XVI al XVIII'.

En consecuencia, el listado de males ocurridos entre ellos es largo: diarrea y disentería como las más frecuentes y mortales; helmintiasis, neumonía, abscesos pulmonares, pian, sífilis, anquilostomiasis caquéctica, viruela, tétanos. La fiebre "nerviosa" -quizá una fiebre tifoidea-. Otras enfermedades de vector como el paludismo, fiebre amarilla y el mal del sueño o también llamada tripanosomiasis fueron comunes entre la población africana.

Por lo tanto, el daño causado por estos males entre los esclavos negros, como ya mencionamos fue alto, sin embargo, aquellos que sobrevivieron al llegar a América tuvieron un sistema inmunitario fortalecido. Por el contrario, al mezclarse con los indígenas, el menoscabo fue mortal para estos últimos.

Hay un consenso tanto en Bartolomé de las Casas como en Motolinía sobre la inexistencia de paludismo y la fiebre amarilla entre los indígenas y ello se debió a que en las partes altas de regiones como Tenochtitlan los mosquitos transmisores no pudieron adaptarse.

\section{LAS OLAS MORTÍFERAS}

La siguiente epidemia sucede a partir de 1531. Esta ocasión es el sarampión que arrasa con la población. La denominan tepitonzáhuatl, que quiere decir, lepra chica para distinguirla de la viruela. Desde el año de 1532, la orden de los franciscanos, entre ellos Sahagún, se encargarán de realizar una importante labor de apoyo a los

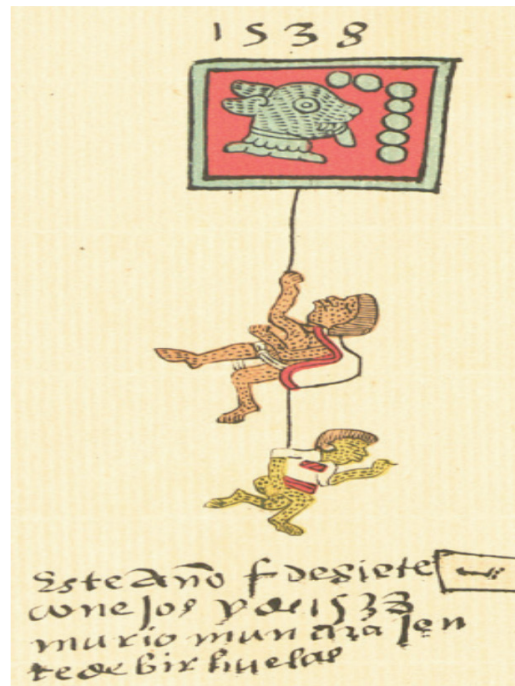

Foto 1. Códice Telleriano- Remensis. Biblioteca Universidad Rostock (Loubat 1901). Enfermos de sarampión ${ }^{9}$.

Fuente: http://www.famsi.org/spanish/research /loubat/Telleriano-Remensis/page_45v.jpg

habitantes a través de la construcción de hospitales y actividades de caridad ${ }^{10}$.

En el Códice Telleriano se representa a los enfermos de sarampión con puntos negros esparcidos a lo largo de todo el cuerpo (Foto 1). La fecha de esta peste va de 1537 a 1538.

Para 1545 otra serie de contagios azota con numerosos padecimientos. Un nuevo brote de viruela (Foto 2) está entre los habitantes prehispánicos. No menos agresivo que el anterior con 80 mil enfermos. Sahagún ${ }^{2}$ lo narró de esta forma:

Cuando se fueron los españoles de México... primero se difundió entre nosotros una gran peste, una enfermedad general... sobre nosotros se extendió: una gran destruidora de gente. Algunos bien los tapó por todas partes...en la cara, en la cabeza, en el pecho...no podía acostarse 


\section{LAS EPIDEMIAS DEL MÉXICO PREHISPÁNICO: UN BREVE RECORRIDO HISTÓRICO ITZA NAHOMY GUTIÉRREZ FONSECA}

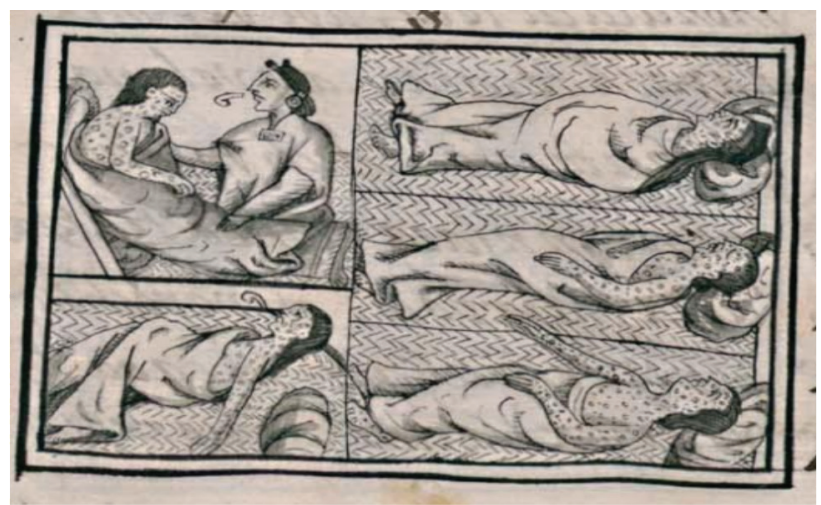

Foto 2. Códice Florentino. Biblioteca Medicea Laurenziana. 1540-1585. Libro XII. Enfermos de viruela.

Fuente: de: http://teca.bmlonline.it/ImageViewer/servlet/ImageViewer?idr=TECA0001504065 \&keyworks=Sahagun\#page/932/mode/2up

cara abajo, ni acostarse sobre la espalda, ni moverse de un lado a otro... dura enfermedad de granos... muchos murieron de ella, pero a muchos se les echó a perder la cara, quedaron cacarañados, cacarizos. Unos quedaron ciegos, perdieron la vista. El tiempo que estuvo en fuerza esta peste duró sesenta días. Hacia Chalco se fue la peste. $Y$ con esto mucho amenguó, pero no cesó del todo.

En la Historia General de las cosas de la Nueva España ya se encuentra un "remedio" para la viruela, Fray Bernardino de Sahagún ${ }^{2}$ (Foto 3) lo planteó de la siguiente forma:

Los hoyos y asperezas del rostro que suelen proceder de las viruelas, o de otras semejantes enfermedades se curan tomándose los orines calientes y lavándose el rostro... lavarse siempre con el zumo caliente de la hierba azpan (no identificada) y después beberá el zumo de la hierba nombrada tlatlauhqui . (Foto 4)

Al hueyzáhuatl se agrega el matlazáhuatl, conocido en España como el tabardillo o tabardete, actualmente el tifus exantemático ${ }^{5}$. Los tratamientos recomendados fueron:

Esta hierba que se llama matlall (Commelina sp.), y revuélvense con agua caliente... esta bebida es contra el tabardete, cuando comienza a aparecer con unas pintas como de cardenillo, y bebiendo esta hierba luego sale fuera; es menester sangrar al enfermo.

La hierba que se llama izataquílitl... molida es provechosa contra el tabardete, molida con agua, bebida luego vomita la cólera o flema.

a. Ángel María Garibay ${ }^{11}$, en el vocabulario que incluye sobre los términos utilizados por Sahagún refiere la palabra Tlatlauhcapatli como una medicina roja, raíz de una planta con fines medicinales y la identifica con el nombre científico de Geranium carolinianum. En el Códice De la Cruz-Badiano ${ }^{12}$, Libro de las hierbas medicinales de los pueblos indígenas, entre las 227 especies enlistadas, se halla el Tlatlanquaye, cuyo nombre científico es Peperomia galioides de la cual, hasta ahora, no se conocen propiedades medicinales, aunque una afín a ella, la Peperomia inaequalifolia se usa con fines cicatrizantes. 


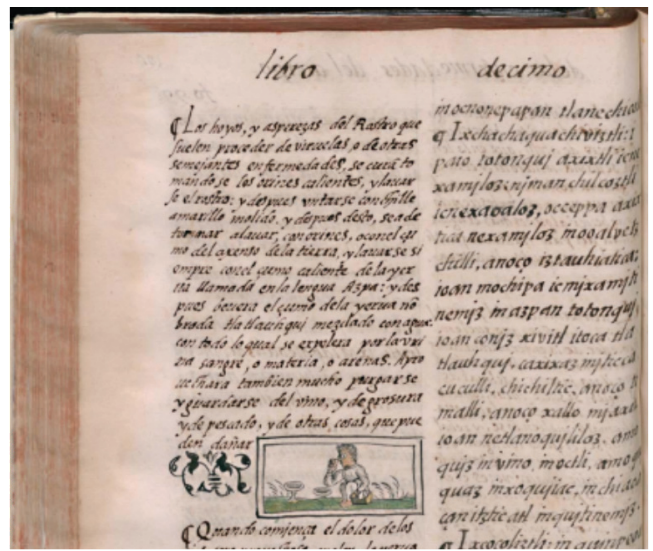

Foto 3. Códice Florentino. Biblioteca Medicea Laurenziana. 1540-1585. Fragmento Libro X.

Fuente: de: http://teca.bmlonline.it/ImageViewer /servlet/ImageViewer?idr=TECA0001504065 \&keyworks=Sahagun\#page/215/mode/1up

Hubo otras enfermedades, que, si bien no han sido identificadas, los síntomas se refieren como: "pujamiento con sangre y juntamente con calenturas, y era tanta la sangre, que les reventaba por las narices". Estas manifestaciones han sido relacionadas con algún tipo de padecimiento febril, hemorrágico ${ }^{5}$. La causa aparente de hecho pudo ser un virus autóctono diseminado por roedores localizados en los campos de cultivo, principalmente en la zona del altiplano. No existe evidencia de que las zonas costeras fueran afectadas $^{6}$.

Finalmente, en el último cuarto del siglo $\mathrm{XVI}$, se presenta la tercera de las epidemias más desastrosas de la Nueva España que junto con la anterior fueron denominadas cocoliztli, Gran pestilencia, tanto por el número de muertes presentadas como por la variedad de manifestaciones clínicas. Se estima que entre ocho a veinte millones de personas fallecieron en ese lapso 6 .

El inicio de este nuevo azote se considera a partir de agosto de $1576^{4}$. Al cocoliztli se le agregan el quechopotzahualiztli, paperas;

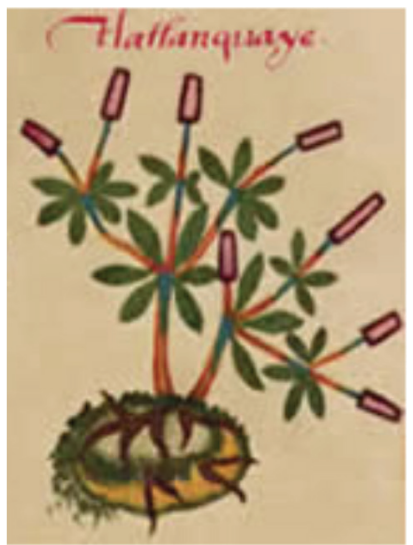

Foto 4. Códice De la Cruz-Badiano. Instituto Nacional de Antropología e Historia. S XVI.

Tlatlanquaye.

Fuente: https://mediateca.inah.gob.mx/repositorio /islandora/object/codice:851\#page/87/mode/1up

tatlaciztli o tos chichimeca, conocida ahora como tosferina ${ }^{4}$ y aquellas transmitidas por el contacto con los esclavos negros traídos de África.

El factor de la desnutrición nuevamente influyó para que entre los indígenas se registrara un mayor número de muertes, aunque esta vez, nadie quedó libre de enfermedad ${ }^{4}$ :

Primeramente, invadió aquellas regiones ocupadas por las tribus indias, las habitadas por indios y etíopes, luego las de población mixta de indios y españoles, más tarde todavía las de etíopes, y ahora finalmente ataca las de españoles.

En consecuencia, el protomédico de la colonia Francisco Hernández ${ }^{13}$ hizo una amplia descripción de esta terrible situación padecida por los habitantes de la Nueva España:

las fiebres eran contagiosas, abrasadoras y continuas, más todas pestilentes $y$, en gran parte letales. La lengua seca y negra. Sed intensa, orinas de color verde marino, verde (vegetal) y negro...pulsos frecuentes y rápidos, más pequeños y débiles; de vez 


\section{LAS EPIDEMIAS DEL MÉXICO PREHISPÁNICO: UN BREVE RECORRIDO HISTÓRICO \\ ITZA NAHOMY GUTIÉRREZ FONSECA}

en cuando hasta nulos. Los ojos y todo el cuerpo, amarillos. Seguía delirio y convulsión, postemas detrás de una o ambas orejas... dolor de corazón, pecho y vientre, temblor y gran angustia y disenterías; la sangre, que salía al cortar una vena, era de color verde o muy pálido, seca y sin ninguna serosidad. Algunos gangrenas y esfacelos invadían los labios, las partes pudendas y otras regiones del cuerpo con miembros putrefactos, y les manaba sangre de los oídos... con el flujo de la sangre de la nariz muchos se salvaban, los demás perecían.

Los atacados de disentería en su mayor parte ordinariamente se salvaba, ni los abscesos detrás de la oreja eran mortales, si en modo alguno retrocediesen, sino que espontáneamente maduraba... o fluyere el pus, tras de lo cual quedaría también eliminada la causa de la enfermedad.

El cocoliztli se volvió para ese tramo final del siglo, en un asunto de importancia para las autoridades novohispanas de tal forma que se hacen enviar a cirujanos para visitar las casas de los enfermos y elaborar informes para encontrar una cura ante el mal. El arzobispo D. Pedro Moya y quien después sería nombrado VI Virrey de la Nueva España, lanzó una campaña entre los integrantes de su curia para apoyar a las víctimas del cocoliztli.

Lo anterior como parte de una nueva política de asistencia social y también para contrarrestar el renacer de las ideas de castigos divinos y aciagas predicciones que por la creciente ola de enfermos y muertes por las que atravesaba la sociedad, tenían un caldo de cultivo.

El protomédico Hernández llegó a la conclusión de que un veneno era responsable de tan grande mortandad. El desequilibrio entre los distintos humores del cuerpo ocasionaba este "veneno" y por ello, era necesario una composición farmacéutica denominada atríaca, cuyo propósito era purgar el cuerpo. Por ello, Hernández decidió modificar la receta original europea con medicamentos indígenas ${ }^{4}$. Es así como ocupa la hierba medicinal coanenepilli (Foto 5) y la piedra eztetl. (Foto 6) Sahagún ${ }^{2}$ los describe de esta forma:

(Hierba) que tiene la raíz blanca y tiesa, y es algo dulce, y de color moreno lo superficial, y el meollo es blanco. Una de estas raíces se toma en cuatro veces para purgar; desechar los malos humores por la boca y por la cámara; bébese poca para purgar; (y) también templa el demasiado calor.

Piedra medicinal que se llama eztetl, la cual es provechosa para restañar la sangre de las narices; tomándola en la mano o poniéndola en el cuello, de tal manera que toque en la carne.

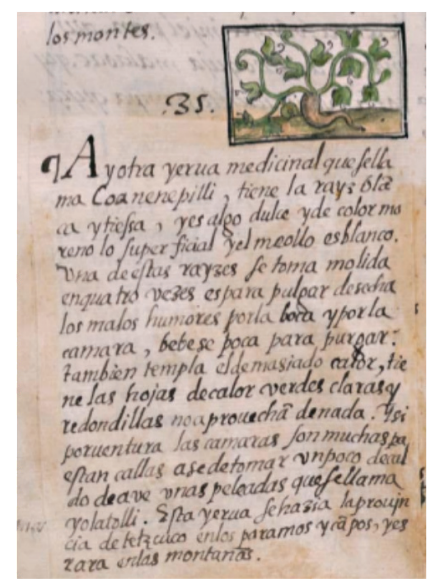

Foto 5. Códice Florentino. Biblioteca Medicea Laurenziana. 1540-1585. Libro XI. Fragmento donde se refiere al uso del coanenepilli.

Fuente: de: http://teca.bmlonline.it/ImageViewer /servlet/ImageViewer?idr=TECA0001504065 \&keyworks=Sahagun\#page/603/mode/1up 


\section{LAS EPIDEMIAS DEL MÉXICO PREHISPÁNICO: UN BREVE RECORRIDO HISTÓRICO ITZA NAHOMY GUTIÉRREZ FONSECA}
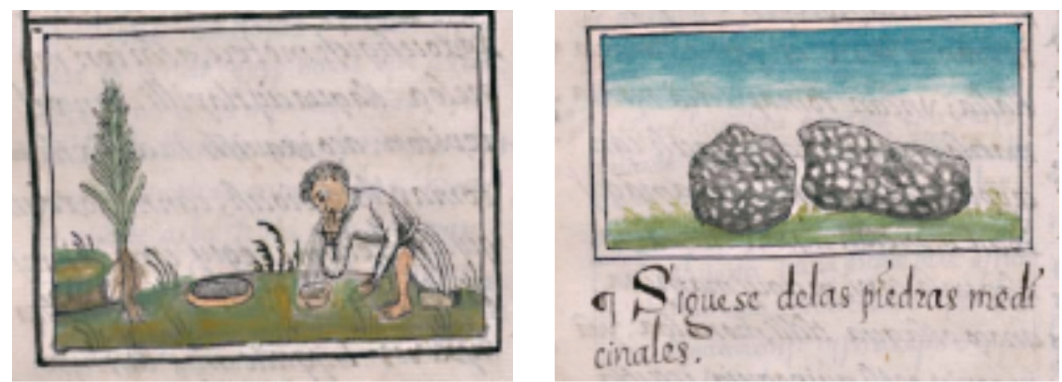

Foto 6. Códice Florentino. Biblioteca Medicea Laurenziana. 1540-1585. Libro XI. Fragmento donde se refiere al uso del eztetl.

Fuente: http://teca.bmlonline.it/ImageViewer/servlet/ImageViewer?idr=TECA0001504065 \&keyworks=Sahagun\#page/658/mode/2up

Fuente: de: http://teca.bmlonline.it/ImageViewer/servlet/ImageViewer?idr=TECA0001504065 \&keyworks=Sahagun\#page/670/mode/2up

\section{CONCLUSIONES}

Las epidemias eran ya conocidas en las culturas prehispánicas y la mayor parte de ellas ocasionadas por factores como inundaciones, guerras, sequías, hambrunas. La desnutrición de largos periodos sin alimento, acrecentó los efectos negativos entre la población.

La llegada de nuevos grupos poblacionales a América trajo otras enfermedades que no hizo sino agravar la situación ya existente cuando las epidemias se presentaban. La guerra no sólo propicio la movilización de sectores enteros de personas, pero también la acelerada devastación a causa de estos nuevos padecimientos.

El proceso de colonización trajo también nuevos métodos de atención a los enfermos a través de las órdenes mendicantes quienes, con su trabajo no sólo de evangelización, sino en la construcción de hospitales para el cuidado y protección de los afectados por las epidemias realizaron toda una actividad social y de caridad. La tradición herbolaria de los pueblos prehispánicos se mezcló con la medicina europea enriqueciendo el conocimiento sobre las enfermedades y su atención.
A lo largo del periodo novohispano se dieron otros brotes epidémicos: 1769, 1778 y aún en 1804, previo a la campaña de vacunación del Dr. Balmis. Sin embargo, ninguna ha quedado en los registros como aquellas del encuentro entre dos mundos.

\section{REFERENCIAS}

1. Díaz del Castillo B. Historia verdadera de la Conquista de la Nueva España. México: Porrúa; 2020.

2. Sahagún B. Historia General de las cosas de la Nueva España. México: Porrúa; 2020.

3. Benavente, T. Historia de los indios de la Nueva España. México: Porrúa; 2020.

4. Malvido E y Viesca C. La epidemia de cocoliztli de 1576. Historias. Estudios Históricos. INAH. [Internet] 1985 oct.-Dic.: 26-33.

5. Mandujano Sánchez A., Camarillo Solache L. y Mandujano MA. Historia de las epidemias en el México antiguo. Algunos aspectos biológicos y sociales. Casa del Tiempo [Internet] 2003 abril (4): 9-21.

6. Carral Cuevas J. Efectos institucionales del cocoliztli en la Nueva España. 1545-1548. México: Universidad Iberoamericana; 2008. 


\section{LAS EPIDEMIAS DEL MÉXICO PREHISPÁNICO: UN BREVE RECORRIDO HISTÓRICO \\ ITZA NAHOMY GUTIÉRREZ FONSECA}

7. De Torquemada FJ. Primera parte de los veintiún libros rituales y monarquía indígena, con el origen y guerras, de los indios occidentales, de sus poblaciones, descubrimiento, conquista, conversión y otras cosas maravillosas de la misma tierra. [Internet]. Valladolid: Biblioteca Digital de Castilla y León: Junta de Castilla y León. Consejería de Cultura y Turismo; 1723 en Mandujano Sánchez et al. Historia de las epidemias en el México antiguo. Algunos aspectos biológicos y sociales. Casa del Tiempo [Internet] 2003 abril (4): 10.

8. De Somolinos d'Ardois G. Las epidemias en México durante el siglo XVI. En: Florescano E y Malvido E. (comps.) Ensayos sobre la historia de las epidemias en México. México: Instituto Mexicano del Seguro Social; 1982. p. 205-214.

9. De Alva Ixtlilxóchitl. F. Relación de la venida de los españoles y principio de la ley evangélica. en Díaz del Castillo B. Historia verdadera de la Conquista de la Nueva España. México: Porrúa; 2020. p. 806.
10. Sánchez Pérez MC y Mandujano Valdés MA. Apuntes para la historia de la asistencia social y la rehabilitación. México: Universidad Autónoma Metropolitana. Unidad Xochimilco; 2014.

11. Garibay AM. Numeración, anotación y apéndices. En Sahagún, Bernardino. Historia General de las cosas de la Nueva España. México: Porrúa; 2020.

12. De la Cruz M y Badiano J. Códice De la Cruz-Badiano. Libro de las hierbas medicinales de los pueblos indígenas. [Internet]. México: Mediateca del Instituto Nacional de Antropología e Historia (INAH); c Siglo XVI [citado 2020].

13. Somolinos D'Ardois G. Hallazgo del manuscrito sobre el cocoliztli. En: Florescano E y Malvido E. (comps.) Ensayos sobre la historia de las epidemias en México. México: Instituto Mexicano del Seguro Social; 1982. p. $374-376$

\begin{tabular}{|l|l|} 
Itza Nahomy G. Fonseca. Licenciada en Economía y Maestra en Bioética \\
por la Escuela Superior de Medicina del Instituto Politécnico Nacional en \\
Cd. de México. Diplomada en Bioética, Salud y Derecho por el Instituto de \\
Investigaciones Jurídicas, UNAM. Ha sido Jefa de Finanzas en el Hospital \\
Central de Cruz Roja Mexicana y Docente en la Escuela de Enfermería de \\
la misma institución. Ha publicado en el suplemento de salud Letra S del \\
periódico La Jornada en Cd. de México y participado en temas de bioética, \\
arte y medicina en el Foto Museo 4 Caminos.
\end{tabular}

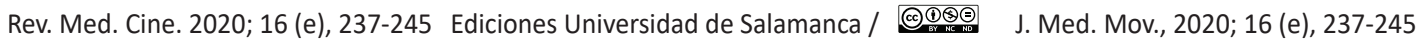

